\title{
Care-Seeking Behaviour and Treatment Practice for Malaria in Children Under 5 Years: A Cross Sectional Study in Idu Community, Abuja, Nigeria
}

\author{
Godspower Onavbavba $^{1^{*}} \quad$ Vincent Odunayo Alemede $^{2} \quad$ Abubakar Mustapha Danraka $^{1}$ \\ Ngozi Okoronkwo ${ }^{1}$ \\ 1.National Institute for Pharmaceutical Research and Development, Idu, Abuja, Nigeria \\ 2.Esoma Pharmaceuticals, Kubwa Abuja, Nigeria.
}

\begin{abstract}
Malaria is one of the major causes of death for children who are under 5 years of age. African children are most affected because of the prevalence of the disease in the Continent. This study aimed at assessing care-seeking behaviour and treatment practice for malaria in children under 5 years of age. A cross sectional study was conducted by administering a self completed questionnaire to caregivers in Idu community, Abuja. Data were analysed using Statistical Package for Social Sciences. Findings revealed that all the study participants had encountered malaria in their children under 5 years, majority of the participants $(55 \%)$ sought treatment from pharmacy or clinic when their under 5 years old child had malaria. More than a quarter of the study participants sought treatment within 24 hours following malaria infection in their children. For those that delayed in seeking treatment, majority of them indicated lack of finance as a reason for delay. Government therefore need to put policy in place to ensure that children under 5 years of age have unhindered access to malaria treatment so as to prevent loss of lives.
\end{abstract}

Keywords: Malaria, Children, Nigeria, Under 5 years, caregivers

DOI: $10.7176 / \mathrm{JBAH} / 11-12-04$

Publication date:June $30^{\text {th }} 2021$

\section{Background}

Malaria is a mosquito-borne infectious disease of humans and animals caused by parasitic protozoan that belong to the genus plasmodium (WHO, 2014). The disease can be transmitted through the bite of an infected female anopheles mosquito which introduces the organisms from its saliva into human blood. In the blood, the parasite travels to the liver to mature and reproduce and the symptoms usually begins 10-15 days following bite by the female anopheles mosquito (WHO, 2014). Malaria is a major cause of morbidity and mortality in Africa. It has resulted in an estimated 216 million infections and about 655,000 deaths in 2010. Cases of infections and deaths of about $81 \%$ and $91 \%$ occurred respectively in the African Sub-region (WHO, 2015).

Children who are under 5 years of age and pregnant women bear the brunt of the parasitic infection. Plasmodium falciparum, the most virulent species of malaria parasite is the prevalent species found in subsaharan Africa, thereby resulting in a greater impact of the disease in the region. In areas where malaria is endemic, most deaths from the disease occur within a few hours of admission (Olupot-Olupot and Maitland, 2013). Epidemiologically, malaria in Nigeria can be described as holoendemic, implying an all year round malaria transmission with higher rates in wet season than in dry season. During peak transmission, over $70 \%$ of children aged 1-10 years suffer high rate of disability with the associated high parasite density whereas the adult population enjoys high level of immunity. Global warming poses a threat that present a risk of serious epidemics through an extension of malaria into the high lands and plateau areas of Africa previously considered free from malaria (Ukwe, 2012).

Children under 5 years of age are one of the most vulnerable groups affected by malaria. Partial immunity to the disease is acquired during childhood in areas with high transmission. In these setting majority of deaths occurs in children without immunity to the disease. Severe anaemia, hypoglycemia and cerebral malaria are features of severe malaria often commonly seen in children than in adults (WHO, 2015). A search conducted on extant literature revealed that only few studies have been undertaken in this area as it relates to Nigeria context. This study therefore aimed at assessing care-seeking behaviour and treatment practice for malaria in children under 5 years of age in a community in Abuja.

\section{Methods}

A cross sectional study was undertaken in Idu community located in Abuja, Federal Capital Territory, Nigeria. The participants were made up of caregivers who were currently taking care of a child or children that are under 5 years of age, and also residing within the community.

A well structured questionnaire was designed for the study. A pilot test was first carried out by administering the questionnaire to 20 participants. The response received did not warrant any major change. 
The purpose of the questionnaire was explained to the study participants before administration. Maximum effort was made to maintain the confidentiality of the participants by omitting names of the respondents and making sure no information provided is traceable to them. Appropriate instructions about filling the questionnaire were given.

Convenience sampling strategy was adopted to administer 300 copies of questionnaire. Data retrieved were entered into Statistical Packages for Social Sciences software version 25 for descriptive statistical analysis.

Ethical approval was obtained from Federal Capital Territory Health Ethics Committee prior to the commencement of data collection. Participation in the study was voluntarily, and informed consent was obtained from each participant before the administration of questionnaire.

\section{Results}

\subsection{Demography}

Female participants were in the majority $(70 \%)$, those without formal education were relatively few $(8.0 \%)$, and close to half of the respondents $(47.5 \%)$ were self-employed. Other relevant details relating to sociodemographic characteristics are presented in table 1 below.

\section{Table 1: Socio Demographic Characteristics}

\begin{tabular}{|c|c|}
\hline Variables & Frequency $(\%)$ \\
\hline \multicolumn{2}{|l|}{ Age (years) } \\
\hline$\leq 20$ & $13(6.5)$ \\
\hline $21-26$ & $57(28.5)$ \\
\hline $27-32$ & $52(26.0)$ \\
\hline $33-38$ & $51(25.5)$ \\
\hline 39 and above & $27(13.5)$ \\
\hline \multicolumn{2}{|l|}{ Gender } \\
\hline Female & $140(70.0)$ \\
\hline Male & $60(30.0)$ \\
\hline \multicolumn{2}{|l|}{ Level of Education } \\
\hline No formal education & $16(8.0)$ \\
\hline Primary education & $24(12.0)$ \\
\hline Secondary school & $91(45.5)$ \\
\hline $\mathrm{OND} / \mathrm{NCE}$ & $26(13.0)$ \\
\hline First degree/HND & $35(17.5)$ \\
\hline Post graduate & $8(4.0)$ \\
\hline \multicolumn{2}{|l|}{ Occupation } \\
\hline Self-employed & $95(47.5)$ \\
\hline Civil servant & $13(6.5)$ \\
\hline Employed in private organisation & $61(30.5)$ \\
\hline Student & $21(10.5)$ \\
\hline Others & $10(5.0)$ \\
\hline \multicolumn{2}{|l|}{ Average Monthly Income } \\
\hline Below $\$ 5000$ & $16(8.0)$ \\
\hline$¥ 5,000-\approx 30,000$ & $117(58.5)$ \\
\hline$¥ 30,000-\$ 100,000$ & $56(28.0)$ \\
\hline$\$ 100,000$ and above & $11(5.5)$ \\
\hline \multicolumn{2}{|l|}{ Caregiver Relationship with Child } \\
\hline Mother & $133(66.5)$ \\
\hline Father & $47(23.5)$ \\
\hline Others & $20(10.0)$ \\
\hline
\end{tabular}

\subsection{Treatment Seeking Behaviour and Practice Towards Management of Malaria in Children Under 5} years

All the respondents indicated that their child have been infected with malaria previously, about a third of the participants indicated laboratory test as method of diagnosis for their child or ward. Further details about treatment seeking behaviour are presented in table 2 below. 
Table 2: Treatment-Seeking Behaviour Towards Malaria

\section{Statement}

Has your child ever been infected with malaria

Yes

No

Method of diagnosis

Medical laboratory test

Self-diagnosis

Signs and symptoms present

All of the above

Where treatment was sought from

Clinic

Traditional healer

Pharmacy

Look for local herbs

No where

Decision on where and when child should go for treatment

Mother

Father

Others

\section{Frequency $(\%)$}

$200(100.0)$

$0.0(0.0)$

$62(31.0)$

$41(20.5)$

$60(30.0)$

$37(18.5)$

$110(55.0)$

$8(4.0)$

$61(30.5)$

$13(6.5)$

$8(4.0)$

$127(63.5)$

$67(33.5)$

$6(3.0)$

\subsection{Practice Towards Malaria}

Close to half $(45.5 \%)$ of the study participants indicated that they sought treatment for their child between 2 to 3 days following malaria infection, and about a third of the study participants who did not seek treatment immediately indicated that they engaged in self medication. Other relevant details on practice towards malaria management are presented in table 3 below.

Table 3: Practice Towards Management of Malaria

\begin{tabular}{ll}
\hline Variable & Frequency (\%) \\
\hline How soon was treatment sought after suspecting malaria? & $78(39.0)$ \\
One day (within 24 hours) & $91(45.5)$ \\
$2-3$ days & $19(9.5)$ \\
$4-6$ days & $4(2.0)$ \\
7 days or more & $8(4.0)$ \\
I don't know & \\
What was done by those who did not seek treatment immediately $(\mathrm{n}=122)$ & $62(50.81)$ \\
Self-medication & $35(28.69)$ \\
Use of local herbs & $7(5.74)$ \\
Hydrotherapy & $13(10.66)$ \\
Wait while observing child's condition & $5(4.10)$ \\
Nothing & \\
Reasons for delay in seeking treatment (n = 122) & $47(38.52)$ \\
Lack of finance & $10(8.20)$ \\
Distance to health centre & $4(3.28)$ \\
No free time to take child to health facility & $23(18.85)$ \\
Gave child drug at home & $38(31.14)$ \\
Child's condition was not severe & \\
How often healthcare facility is visited when child is sick & $45(22.5)$ \\
Always & $137(68.5)$ \\
Sometimes & $18(9.0)$ \\
Never & \\
\hline
\end{tabular}

\section{Discussion}

Findings from this study shows that all the study participants indicated that their children had been infected with malaria previously, suggesting malaria was not new to the participants. This finding was however expected considering the level of malaria prevalence in Nigeria. Only about a third of the study participants seems to confirm malaria by medical laboratory test, whilst a similar proportion indicated using the signs and symptoms present to diagnose malaria. Although medical laboratory test is important, early recognition of malaria by caregivers can go a long in saving the life of a child (Lim et al., 2012), as this can allow for early commencement of treatment prior laboratory test. Collectively, a strong majority of the respondents indicated 
that treatment was sought from clinic or pharmacy when their children were infected with malaria suggesting that the caregivers took the health of their children seriously. Also, the reason for seeking treatment in clinic or pharmacy may be as a result of confidence in healthcare personnel manning such facilities (Abuya et al., 2007; Ajayi et al., 2008) as well as satisfaction with pharmaceutical care services (Onavbavba et al., 2019; Onavbavba et al., 2020).

Slightly above a third of the respondents commenced treatment within 24 hours following malaria infection and this is in line with World Health Organization guideline on malaria treatment (Ezedinachi et al., 2014). Uncomplicated malaria can progress rapidly to severe malaria if effective treatment is not started on time. Findings in this study suggest that proper enlightenment of caregivers about malaria needs to be intensified so as to help prevent the progression of uncomplicated malaria to a more critical stage.

Half of the sample who did not seek immediate medical care were engaged in self medication. This finding suggests that majority of the caregivers who failed to seek immediate medical care for their children were undermining the dangers of malaria children under 5 years of age. Malaria has been identified as the probable cause of $4 \%$ of infant deaths and $25 \%$ of deaths in children aged 1 to 4 years (Greenwood et al., 1987). The disease is the major cause of death and severe illness among children in many parts of Africa (Greenwood et al., 1991).

This study further showed that the reason for delay in seeking treatment as indicated by more than a third of the participants is as a result of financial constraint. This finding is a reflection of the community where this study was conducted as majority of the inhabitant in the locality were living below 1.90 US dollar per day. This Finding also corroborate previous finding that reported lack of finance as a barrier to accessing healthcare services (Chuma et al., 2010).

\section{Conclusion}

This study has revealed attitude and practice of caregivers in the treatment of malaria in children under 5 years of age. It can be seen from this study that poverty has a role to play in seeking treatment. Majority of the study participants sought treatment from healthcare facilities when their child or children were infected with malaria. However, majority of those who did not seek treatment immediately in healthcare facility attributed the reason for not seeking immediate treatment to lack of finance. This portends that there is need for government to intensify efforts to make malaria treatment totally free for children who are under 5 years of age, as doing this will prevent death as a result of malaria in this age group.

\section{References}

Abuya TO, Mutemi W, Karisa B, Ochola SA, Fegan G, Marsh V (2007). Use of over-the-counter malaria medicines in children and adults in three districts in Kenya: implications for private medicine retailer interventions. Malaria journal. 6(1):1-10.

Ajayi IO, Falade CO, Bamgboye EA, Oduola AM, Kale OO (2008). Assessment of a treatment guideline to improve home management of malaria in children in rural south-west Nigeria. Malaria journal. 7(1):1-12.

Chuma J, Okungu V, Ntwiga J, Molyneux C. Towards achieving Abuja targets: identifying and addressing barriers to access and use of insecticides treated nets among the poorest populations in Kenya. BMC Public Health. 2010 Dec;10(1):1-4.

Ezedinachi EN, Odey FA, Esu EB, Oduwole OA, Nwachuku NS, Meremikwu MM (2014). Treatment Delay Attitude of Caregivers in Management of Childhood Malaria in Rural Communities in Nigeria. Journal of Advances in Medicine and Medical Research. 8:5577-86.

Greenwood B, Marsh K, Snow R. Why do some African children develop severe malaria?. Parasitology today. 1991 Jan 1;7(10):277-81.

Greenwood BM, Bradley AK, Greenwood AM, Byass P, Jammeh K, Marsh K, Tulloch S, Oldfield FS, Hayes R. Mortality and morbidity from malaria among children in a rural area of The Gambia, West Africa. Transactions of the Royal Society of Tropical Medicine and Hygiene. 1987 Jan 1;81(3):478-86.

Lim S, Yasuoka J, Poudel KC, Ly P, Nguon C, Jimba M (2012). Promoting community knowledge and action for malaria control in rural Cambodia: potential contributions of Village Malaria Workers. BMC research notes. 5(1):1-10.

Olupot-Olupot P, Maitland, K (2013). "Management of severe malaria: Results from recent trials". Advances in Experimental Medicine and Biology. 764: 241-50.

Onavbavba G, Danraka AM, Galadima IH, Isibor AA (2020). Assessment of Patient Satisfaction with Pharmaceutical Care Services in Community Pharmacies within Abuja. Sch Acad J Pharm. 9(2):51-57. DOI: https://doi.org/10.36347/sajp.2020.v09i02.001

Onavbavba G, Owonaro AP, Eniojukan FJ (2017). Patient Satisfaction with Pharmaceutical Care Services in Selected Health Facilities in Delta State, South-South of Nigeria. Ortho \& Rheum Open Access. 8 (3):555739. DOI: https://doi.org/10.19080/OROAJ.2017.08.555739 
Ukwe CV, (2012) Malaria In: Therapeutic Basis Of Clinical Pharmacy In The Tropics, C.N. Aguwa (Ed.) Snap Press Limited, Enugu, Nigeria, pp 279-296.

World Health Organization (2014). Malaria: fact sheet. World Health Organization. Regional Office for the Eastern Mediterranean.

World Health Organization (2015). "The Roll Back Malaria Strategy For Improving Access to Treatment Through Home Management of Malaria',

World Health Organization (2015). Guidelines for the treatment of malaria. 